\title{
Varieties of Pathological Self-mutilation
}

\author{
ARMANDO R. FAVAZZA ${ }^{1}$ and RICHARD J. ROSENTHAL ${ }^{2}$ \\ ${ }^{1}$ Department of Psychiatry, University of Missouri, Columbia, Missouri 54201, USA \\ ${ }^{2}$ Department of Psychiatry, University of California, Los Angeles, California 90029, USA
}

\begin{abstract}
Pathological self-mutilation appears as a non-specific symptom as well as a specific syndrome. Since psychotic persons may commit horrifying acts, such as enucleation of an eye or amputation of a body part, identification of high risk patients is crucial. Stereotypical self-mutilation, such as head banging and.biting off of fingertips, is associated with mental retardation and with the syndromes of Lesch-Nyhan, deLange, and Tourette. This type of self-mutilation is the focus of biological research or endorphins and on dopamine receptors. Skin cutting and burning, the most common type of self-mutilation, is often associated with personality disorders, post-traumatic stress disorder, and multiple personality disorder. When cutting and burning become established as responses to disturbing psychological symptoms on environmental events, a specific Axis I impulse disorder known as Repetitive Self Mutilation may be diagnosed. Patients with this newly identified syndrome may alternate their direct acts of self-mutilation with eating disorders and episodic alcoholism.
\end{abstract}

\section{Introduction}

Self-mutilation, the deliberate destruction or alteration of body tissue, ranks among the most puzzling activities in the vast repertoire of human behavior. The oldest, detailed literary account of self-mutilation is provided by Herodotus who describes how Cleomenes, a Spartan leader gone psychotic, took a knife and, beginning on his shins, "sliced his flesh into strips, working upwards to his thighs, hips and sides until he reached his belly, which he chopped into mincemeat." In the New Testament Mark tells of Jesus' encounter in the lands of the Gadarenes with a depressed, demon-infested man who "always, night and day, was in the tombs, crying and cutting himself with stones."

Although the exact number is unknown, several authors have estimated the prevalence of pathological, self-harm behavior to range from 400 to 700 persons per 100000 population per year (Whitehead et al., 1973; Pattison and Kahan, 1983; Favazza and Conterio, 1988). Self-mutilators in general comprise three groups: those who are psychotic, those who perform stereotypical acts of self-harm, and those who are cutters and burners. The last group contains repetitive self-mutilators who may have a distinct disorder of impulse control. 


\section{Psychotic Self-Mutilation}

Psychotic self-mutilation fortunately is an uncommon behavior that may strain the credulity of care-givers. A 20-year-old acutely psychotic, schizophrenic man, for example, removed all the skin from his face so that he was "unrecognizable as a living being" (Scheftel et al., 1986). Favazza (1987) has estimated that 500 cases of deliberate eye enucleation occur yearly in the United States. The prototypical enucleation is a young male who becomes psychotically depressed while in a county jail. Bibles are considered suitable reading for prisoners and enucleators often point to the admonition found in Matthew and Mark, that one should remove an offending eye, as an important factor in their decision to mutilate themselves. Self-enucleation interestingly appears to be a behavior found only in Christian culture areas, although many cultures have myths and folk-tales about it.

Deviant male genital self-mutilators tend to be psychotic at the time of the act, the most frequent diagnoses being schizophrenia and major depression; they have an average age of 32 years. Alcohol ingestion prior to the act may be a contributing factor in about 25 per cent of cases. Removal of the testicles is somewhat more common than removal of the penis, which, in turn, is more common than removal of both organs. There is no correlation between a specific diagnosis and the genital organ selected for mutilation. In descending order, the reasons provided by patients for their self-mutilation are most likely to be as follows: the wish to be or delusions of being female; concerns about homosexuality; relief of physical pain or somatic illness; guilt over sexual urges such as incest; religiosity; command hallucinations; and punishment for failures in the male role.

Occasionally one encounters non-psychotic self-castrators, e.g. men with character disorders who act impulsively or transsexuals who have premeditated their actions. The genital mutilations of transsexuals are usually well planned and rather neatly done. While many psychotic persons castrate themselves impulsively and with little regard to surgical technique, transsexuals typically have studied the procedure and perform it in a controlled fashion with a minimum of unnecessary trauma.

There is no specific treatment for psychotic self-mutilation other than attention to the basic disorder. Most of the time it is impossible to reattach a severed body part, therefore prevention is crucial. At high risk are psychotic patients who have engaged in previous self-mutilation, who manifest hyperreligiosity, quote the Bible, and adopt a Christ-like appearance, or who radically alter their physical appearance, e.g. shave their heads or put on a strange costume (Sweeny and Zamecnik, 1981).

\section{Stereotypical Self-Mutilation}

Stereotypical acts of self-mutilation include head-banging, orifice gouging, and biting off of fingertips and lips. This behavior is present in 8-14 per cent of institutionalized mentally retarded persons, and is also found in the syndromes of Lesch-Nyhan, deLange, and Tourette (Robertson et al., 1989). 
Patients and experimental animals who demonstrate stereotypical selfmutilation have been studied in an attempt to understand better the biological components of self-harm. In brief, stereotypical self-mutilation can be induced in some animals by administering dopamine agonists such as caffeine and amphetamine. This behavior is similar to that seen in LeschNyhan syndrome; the hypothetical neurochemical commonality in both is dopamine (probably D1) receptor supersensitivity (Goldstein et al., 1985). Gualtieri et al. (1986) have extended this model to include the self-injurious behavior seen in mental retardation, and have reported modest success in treatment with D1-dopamine blocking agents.

Another biological model implicates endorphins, e.g. self-mutilation is supposedly reinforced by the release of pleasurable endorphins following each act of self-mutilation. Studies on a few mentally retarded selfmutilators treated with naloxone, an opiate antagonist, in order to prevent the reinforcing consequences of self-harm behavior, have been equivocal (Richardson and Zaleski, 1983, 1986). Since some mentally retarded and Lesch-Nyhan patients seem to have a high threshold to pain, naloxone has been given to lower the pain threshold, again with equivocal results in controlling self-mutilation (Sandyk, 1985; Beckwith et al., 1986). Coid et al. (1983) found raised plasma metenkephalin levels in non stereotypical selfmutilators, but the interpretation of this finding is problematic.

\section{Gutters and Burners}

The skin is a fairly simple organ from a physiological perspective, but socially and psychologically it is highly complex. Persons may be judged and much of their fate determined, for example, by the color of their skin. Concepts of beauty are linked to the condition of one's skin. Too, the skin serves as a sort of billboard in which emotional states are displayed. Rage, shame, and fear, for example, may be communicated by flushing, blushing, or blanching of the skin. The skin is also a border between the outer world and the inner world, the environment and the self. Although we sometimes merge our sense of self-identity with that of another person or entity when we fall in love, participate in an intense group experience, or achieve some sort of mystical state, we normally live within our skins. Our skin contains us. All that is enclosed by my skin is me; anything else is not me.

Given the symbolic importance of skin it is not surprising that it is the preferred site for acts of self-mutilation. Most commonly it is cut or burned, but it also may be scratched severely, slapped, stuck with pins, and deliberately infected. In a survey of 245 college students, Favazza et al. (1989) found that 12 per cent admitted to self-mutilation. A majority had cut or otherwise harmed themselves one to four times, while a smaller group admitted to five to ten acts of self-harm, and a few admitted to more than ten acts.

A study of 240 female habitual self-mutilators (Favazza and Conterio, 1989) revealed the typical subject to be a 28 -year-old Caucasian female who 
first harmed herself deliberately at age 14 . Her most common practice was skin cutting (but she also had used other methods such as skin-burning and self-hitting) on more than 50 occasions. The decision to self-mutilate was impulsive and resulted in temporary respite from troublesome psychological symptoms. Cutting, for example, relieved unbearable tension "like popping a balloon". It often terminated periods of depersonalization and provided a sense of control over racing thoughts and rapidly fluctuating emotions. Other reasons (Favazza, 1989a) for indulging in self-harm include venting anger, relief from feelings of alienation, pressure from multiple personalities, inducing a sense of euphoria, titillation, security, and uniqueness, enhancing or diminishing sexual feelings, and manipulation of others.

Diagnostically, utilizing DSM-III-R, these patients are most often considered to have a borderline personality disorder where "recurrent suicidal threats, gestures, or behavior, or self-mutilating behavior" is listed as one of eight diagnostic criteria. DSM-III-R also specifically mentions self-mutilation in multiple personality disorder where it is listed as a complication, in sexual masochism where it is noted that some patients "act on the masochistic sexual urges through binding themselves, sticking themselves with pins, shock themselves electronically, or self-mutilation," and in factitious disorder with physical symptoms where it states that the symptoms may be "self-inflicted, as in the production of abcesses by injections of saliva into the skin". This list is unfortunately incomplete since self-cutting and burning also occurs in anorexia/bulimia nervosa (Favazza et al., 1989), antisocial personality disorder (Virkkunen, 1976), histrionic personality disorder (Favazza, 1987, pp. 223--227), and post-traumatic stress disorder (Greenspan and Samuel, 1989; Pitman, 1990).

\section{Repetitive Self-Mutilation}

Self-mutilative behavior has been considered generally to be a symptom of some underlying disorder such as schizophrenia or borderline personality disorder. In recent years, however, several authors have suggested that cutting and burning may exist as a distinct syndrome.

A number of articles appeared in the 1960s and 1970s describing a "wrist cutting" and "delicate self-cutting" syndrome (Crabtree, 1967; Graff and Mallin, 1967; Grunebaum and Klerman, 1967; Rinzler and Shapiro, 1968; Pao, 1969; Kafka, 1969; Asch, 1971; Novotny, 1972; Rosenthal et al., 1972; Waldenberg, 1972; Suk, 1974). The study by Rosenthal et al. (1972) was perhaps the best conceived in that 24 self-cutting females were compared with a control group. A subgroup of patients who had cut on more than five occasions were identified as "habitual cutters." Siomopolous (1974) felt that habitual cutters suffered from a distinct "impulse neurosis." Although the cited papers had differing emphases several generalizations emerged, namely that persons with the syndrome are mostly females who cut themselves repeatedly to achieve relief from anxiety, self-hatred, and depersonalization. Such persons often have histories of maternal deprivation, of childhood illnesses or injuries, and of problems with sexuality.

The move to identify a self-mutilative syndrome suffered a setback when 
two studies of patients who attempted suicide failed to uncover any wristcutting syndrome (Clendenin and Murphy, 1971; Weissman, 1975). However, both studies were so seriously flawed that their findings must be dismissed. Cutting was considered to be a suicide attempt (we now known that most instances of cutting are not related to suicide) and only those persons whose cuts resulted in a police report or emergency room/hospital treatment were considered. Weissman even stated that cases of "compulsive minor self-mutilation" were excluded from the study! Furthermore and most importantly, single episode cutters were not distinguished from repetitive cutters.

The term "non-fatal, deliberate self-harm" was eventually introduced to described behaviors that included both failed suicides and "many episodes in which actual self-destruction was clearly not intended" (Morgan, 1979). Shortly afterward a differential classification of self-damaging behaviors was developed, the variables being directness, lethality, and frequency, e.g. the decision of a patient in renal failure to terminate dialysis would be classified as a high lethality, indirect, single episode behavior, while repetitive skin-cutting would be a low lethality, direct, multiple episode behavior, (Kahan and Pattison, 1984). The latter behavior was given the name Deliberate Self-Harm syndrome (Pattison and Kahan, 1983).

We have refined and renamed this syndrome Repetitive Self-Mutilation, a disorder of impulse control. While isolated acts of self-mutilation constitute relatively non-specific symptoms in a host of mental disorders, Repetitive Self-Mutilation appears to be a distinct syndrome in which selfmutilative acts become established as repetitive responses to disturbing psychological symptoms or environmental events. Persons with this disorder are preoccupied with harming themselves with consequent destruction or alteration of body tissue, experience an increasing sense of tension immediately prior to an act of self-harm and a sense of relief during the act. The act itself is not associated with conscious suicidal intent and is not in response to a delusion, hallucination, or transsexual fixed idea, or serious mental retardation.

Repetitive self-mutilators often describe the disorder as an addiction and may seek professional help avidly, especially if their acts of self-harm increase in intensity and frequency. Although the natural history of the disorder is unclear, some patients seem to stop harming themselves totally for long periods of time. Many patients have problems with eating and may have a history of, or may develop, anorexia and/or bulimia nervosa. A smaller group may have a history of, or may develop, episodic alcohol abuse. Direct self-mutilative behavior usually ceases when an eating disorder or alcoholism abuse develops, but may return when eating patterns or alcohol use normalizes.

\section{Modern Primitives}

Favazza (1987) has contrasted pathological self-mutilation with culturally sanctioned practices in which persons mutilate themselves (self-flagellation), voluntarily allow themselves to be mutilated (aboriginal penis slicing), or 
engage in mutilative practices to fulfill social expectations (circumcision of small children). These culturally sanctioned practices are purposeful in that they are thought to foster the goals of healing, religious faith, and social amity. The Flathead (Chinook) Indians of North America, for example, strapped their infants on special boards and compressed their heads with flat pieces of wood in order to produce a head shape that clearly differentiated tribal members from those of other tribes. Another example is the Sun Dance of the Plains Indians. In this holy ceremony, spiritually elite braves freed themselves from the bonds of the flesh by ripping open the muscles of their chest.

We would like to call attention to a growing phenomenon called "modern primitivism" in which persons engage in self-mutilation in emulation of primitive groups. The insertion of metal rings in breast, labial, penile, and scrotal tissue serves the purpose of sexual titillation, especially in the homosexual subculture. However, the leading proponents of modern primitivism cite loftier purposes for body piercing, ritual blood letting, scarification, and other behaviors such as penis stretching, skin pinching, foot binding, branding, and hanging from hooks attached to the skin. Proponents note that while one is powerless to change the world, individuals can change what they do have power over, namely their bodies. For them, television watching encourages passivity and programs people to accept a reality that is merely a simulation of life. Through self-mutilation persons are able to feel real pain and to participate in life. Self-mutilation, they insist, can be a transcendental as well as a therapeutic experience.

A remarkable, illustrated book documenting modern primitivism notes that, "Sometimes women have had a traumatic experience and they'll want to reclaim their sexuality in a way by having a nipple or labia piercing; this becomes a reclaiming ritual that helps undo a lot of shit from their past. And from that moment forward they can go on." The authors also describe how "Couples will get their ears pierced together and have the same earring, or they'll both get their nipples pierced, or one will do it as a gift to the other when they become lovers. These are basic romantic or bonding rituals" (Vale and Juno, 1989). Although the movement is centered in California, modern primitives can be found throughout the world. Piercing Fans International Quarterly is a journal that caters to aficionados

\section{Gonclusion}

Pathological self-mutilation is a non-specific symptom of many mental disorders. In the newest formulation, it is regarded also as a specific syndrome termed Repetitive Self-Mutilation, a disorder of impulse control that, in the DSM-III-R classification, would be coded on Axis I. An analogy can be made with anorexia nervosa. A schizophrenic or personality disordered person may demonstrate significant anorexia. If the criteria for anorexia nervosa are not met, however, the behavior is considered to be a symptom of the primary diagnosis. Once the criteria are met, then a separate diagnosis is made. Likewise, a few acts of self-mutilation may be a 
symptom of a disorder such as borderline or antisocial personality, or posttraumatic stress. Patients whose self-mutilation is habitual should receive the diagnosis of Repetitive Self-Mutilation.

An interesting feature of Repetitive Self-Mutilation is the tendency of patients to manifest other conditions such as eating disorders and episodic alcoholism. In an important theoretical paper, the "uni-impulsive" disorders such as substance abuse, anorexia and bulimia nervosa, pathological gambling, kleptomania, pyromania, the explosive disorders, parasuicides, and self-harm, were reviewed (Lacey and Evans, 1986). The authors found that within each clinical group there are patients who display several disorders of impulse control. Such patients are thought to form a distinct group with protean symptoms; "Thus, if alcohol abuse is addressed in the alcohol treatment unit, the patient may stop drinking but move to food or cutting." In our schema, such patients should receive the diagnosis of Repetitive Self-Mutilation.

A criticism of our concept is that since repetitive self-mutilators usually meet the criteria for a personality disorder, then an additional diagnosis is not necessary, i.e. everyone is a borderline. Our response would be that while most of these patients have borderline, antisocial, or histrionic traits, the development of Repetitive Self-Mutilation results in an exaggeration of these traits. A personality disorder should be diagnosed only if the criteria can be demonstrated to have been present during most of a patient's illness. Once the self-cutting ceases, we find that a number of these patients no longer demonstrate a full-fledged personality disorder, although they may possess pathological personality traits. The situation is analogous to alcoholics whose "personality disorder" disappears after prolonged sobriety.

Finally, we note that the acceptance of this syndrome has significant implications. Repetitive self-mutilators are obviously difficult to treat. Indeed, the literature on their treatment abounds with articles dealing with therapists' countertransference and by a sense of pessimism about dealing with personality disordered patients (Favazza, 1989b).

When Repetitive Self-Mutilation becomes established as a distinct Axis I disorder, then clinicians and researchers will be free to focus on the selfmutilative behaviors themselves and to experiment with innovations in therapy. No consistently successful psychiatric treatment has been developed for an Axis II personality disorder.

\section{References}

Asch, S. S. (1971). Wrist scratching as a symptom of anhedonia. Psychoanalytic Quarterly, 40, 630-637.

Beckwith, B., Cook, D. and Schumacher, K. (1986). Failure of naloxone to reduce selfinjurious behavior in two developmentally disabled females. Applied Research in Mental Retardation, 7, 183-188.

Clendenin, W. W. and Murphy, G. E. (1971). Wrist-cutting: New epidemiological findings. Archives of General Psychiatry, 25, 465-469.

Coid, J., Allolio, B. and Rees, C. H. (1983). Raised plasma metenkephalin in patients who habitually mutilate themselves. Lancet, Sept 3, 545-546. 
Crabtree, L. H. (1967). A psychotherapeutic encounter with a self-mutilating patient. Psychiatry, 30, 91-100.

Favazza, A. (1987). "Bodies Under Siege: Self-Mutilation in Culture and Psychiatry." John Hopkins University Press, Baltimore.

Favazza, A. (1989a). Why patients mutilate themselves. Hospital and Community Psychiatry, 40, $137-145$.

Favazza, A. (1989b). Normal and deviant self-mutilation. Transcultural Psychiatric Research Review, 26, 113-127.

Favazza, A. and Conterio, K. (1988). The plight of chronic self-mutilators. Community Mental Health Journal, 24, 22-30.

Favazza, A. and Conterio, K. (1989). Female, habitual self-mutilators. Acta Psychiatrica Scandinavica, 79, 283-289.

Favazza, A., DeRosear, L. and Conterio, K. (1989). Self-mutilation and eating disorders. Suicide and Life-Threatening Behavior, 19, 352-361.

Goldstein, M., Anderson, L. T., Reuben, R. and Dancis, J. (1985). Self-mutilation in LeschNyhan disease is caused by dopaminergic denervation. Lancet, 338-339.

Graff, H. and Mallin, R. (1967). The syndrome of the wrist cutter. American Fournal of Psychiatry, 124, 36-42.

Greenspan, G. S. and Samuel, S. E. (1989). Self-cutting after rape. American fournal of Psychiatry, 146, 789-790.

Grunebaum, H. V. and Klerman, G. L. (1967). Wrist slashing. American Fournal of Psychiatry, 124, 527--534.

Gualtieri, C. T., Schroeder, S. R., Keppel, J. M. and Breese, G. R. (1986). "Rational pharmacotherapy for self-injurious behavior: Testing the 01 model." Paper presented at the 19th Gatlinburg (Tennessee) Conference on Research and Theory in Mental Retardation and Developmental Disabilities.

Kafka, J. S. (1969). The body as a transitional object. British Fournal of Psychology, 42, 207212.

Kahan, J. and Pattison, E. M. (1984). Proposal for a distinctive diagnosis: The Deliberate Self-Harm syndrome. Suicide and Life-Threatening Behavior, 14, 17--35.

Morgan, H. G. (1979). "Death Wishes? The Understanding and Management of Deliberate Self-Harm." Wiley, New York.

Novotny, P. (1972). Self-cutting. Bulletin of the Menninger Clinic, 36, 505-514.

Pao, P-N. (1969). The syndrome of delicate self-cutting. British Fournal of Medical Psychology, 42, 195-206.

Pattison, E. M. and Kahan, J. (1983). The deliberate self-harm syndrome. American fournal of Psychiatry, 140, 867-872.

Pitman, R. (1990). Self-mutilation in combat-related post-traumatic stress disorder. American Fournal of Psychiatry, 147, 123.

Richardson, J. S. and Zaleski, W. A. (1983). Naloxone and self-mutilation. Biological Psychiatry, 18, 99-101.

Richardson, J. S. and Zaleski, W. A. (1986). Endogenous opiates and self-mutilation. American Fournal of Psychiatry, 143, 938-939.

Rinzler, C. and Shapiro, D. (1968). Wrist cutting and suicide. Mount Sinai Fournal of Medicine (New York), 35, 485-488.

Robertson, M. M., Trimble, M. R. and Lees, A. J. (1989). Self-injurious behavior and the Giles de la Tourette syndrome. Psychological Medicine, 19, 611-625.

Rosenthal, R. J., Rinzler, C., Wallsh, R. and Klausner, E. (1972). Wrist-cutting syndrome: The meaning of a gesture. American Fournal of Psychiatry, 128, 1363-1368.

Sandyk, R. (1985). Naloxone abolishes self-injury in a mentally retarded child. Annals of Neurology, 17, 520 .

Scheftel, S., Nathan, A. S., Razin, A. M. and Mezan, P. (1986). A case of radical facial selfmutilation. Bulletin of the Menninger Clinic, 50, 525-540.

Siomopolous, V. (1974). Repeated self-cutting: An impulse neurosis. American fournal of Psychotherapy, 28, 85-94.

Suk, J. H. (1974). Wrist-cutting syndrome. Neuropsychiatry (Korea), 13, 100-104. 
Sweeney, S. and Zamacnik, K. (1981). Predictors of self-mutilation in patients with schizophrenia. American Fournal of Psychiatry, 138, 1086-1089.

Vale, V. and Juno, A. (1989). "Modern Primitives." Re/Search Publications, San Francisco. Virkkunen, M. (1976). Self-mutilation in antisocial personality (disorder) Acta Psychiatrica Scandinavica, 54, 347-352.

Waldenberg, S. S. A. (1972). Wrist cutting: A psychiatric inquiry. M. Phil. Dissertation, University of London.

Weissman, M. M. (1975). Wrist cutting: Relationship between clinical observations and epidemiological findings. Archives of General Psychiatry, 32, 1166-1171.

Whitehead, P. C., Johnson, F. G. and Ferrence, R. (1973). Measuring the incidence of selfinjury. American Fournal of Psychiatry, 43, 142-148. 


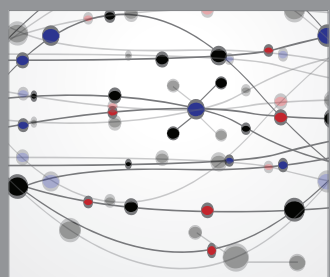

The Scientific World Journal
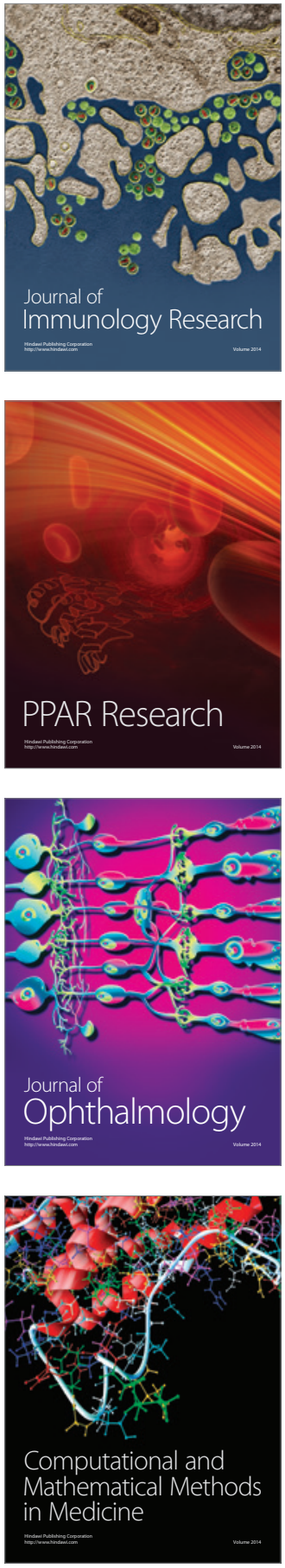

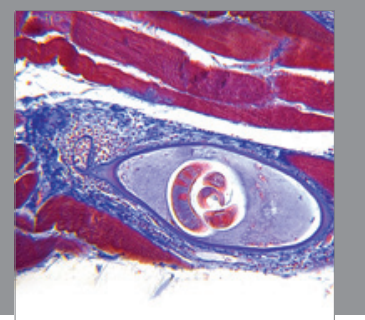

Gastroenterology

Research and Practice
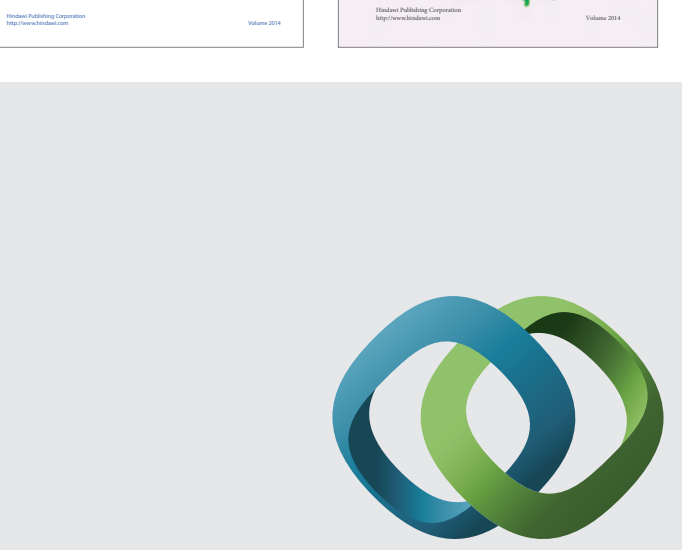

\section{Hindawi}

Submit your manuscripts at

http://www.hindawi.com
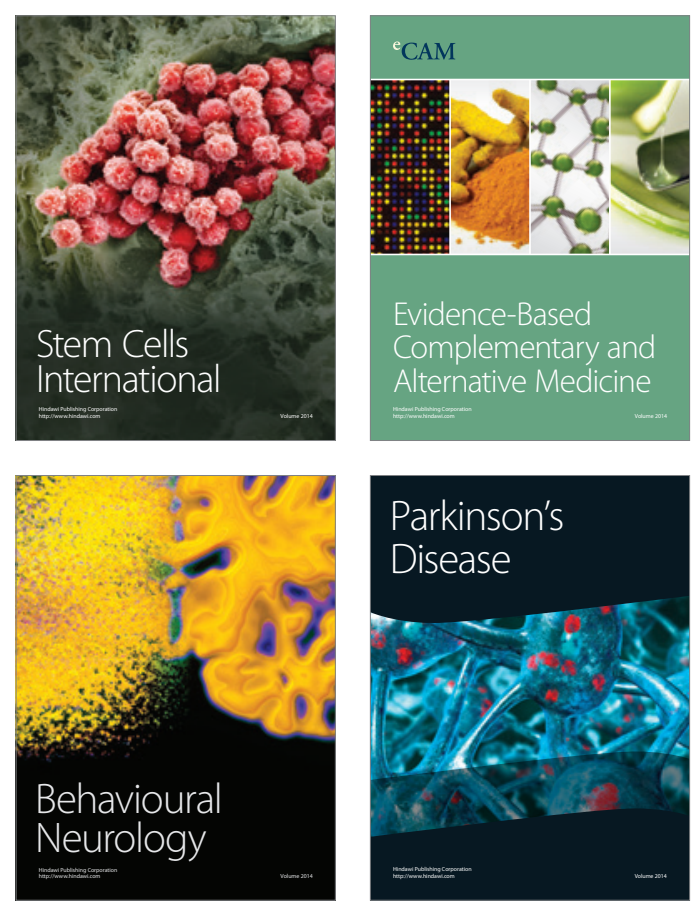

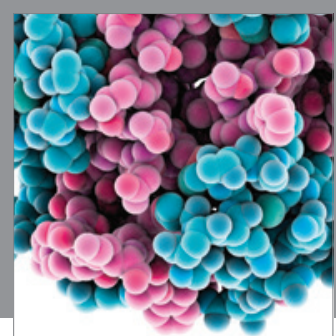

Journal of
Diabetes Research

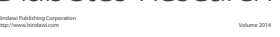

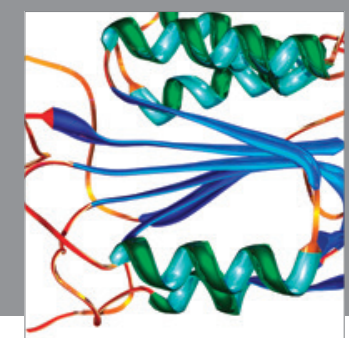

Disease Markers
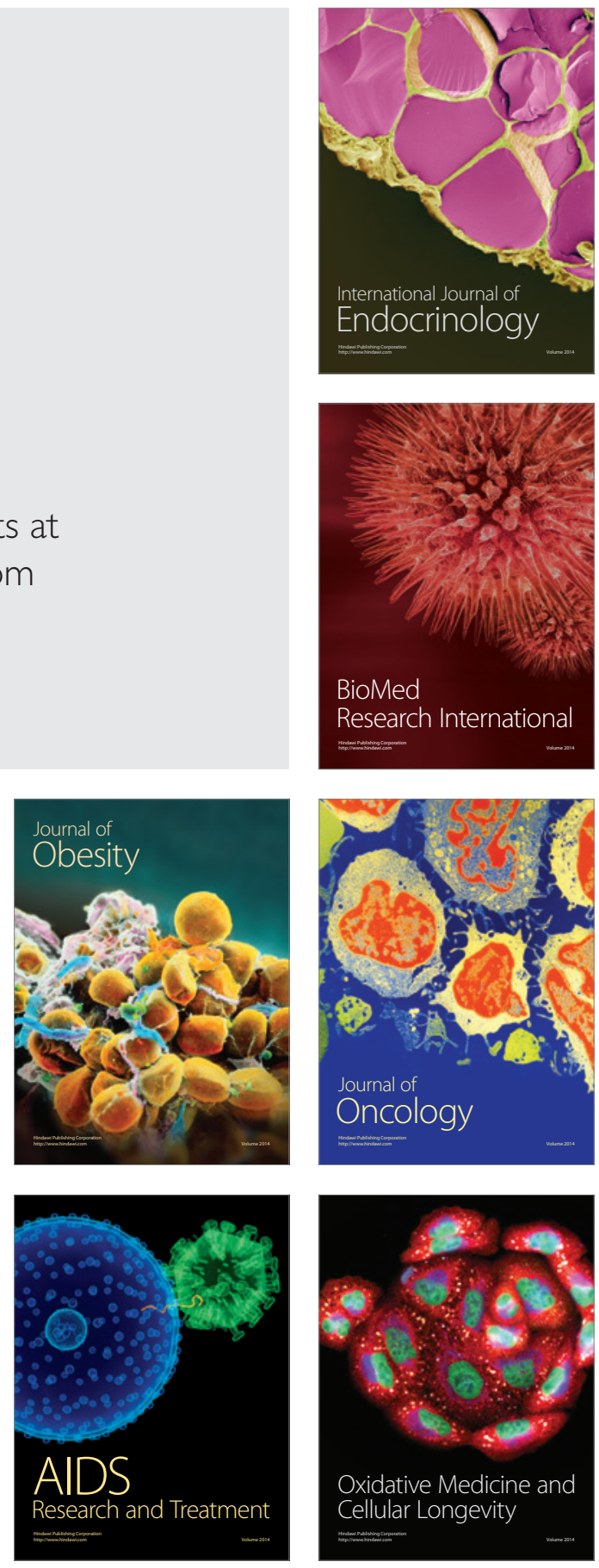